\title{
Mechanical and Wear Behavior of Aluminum-Garnet- Carbon Chill Cast Hybrid Composites
}

\author{
Nityanand Bandekar ${ }^{1}$ and M. G. Anantha Prasad ${ }^{2}$ \\ 'Department of Mechanical Engineering, SDM Institute of Technology, Ujire - 574240, \\ Karnataka, India; nityanand.b1@gmail.com \\ 2Department of Mechanical Engineering, Jyothy Institute of Technology, Bangalore - 560082, \\ Karnataka, India; ananthaprasad1210@yahoo.com
}

\begin{abstract}
Objectives: In recent years, the demand of high performance, light-weight materials is being increased in automotive and aircraft industrial applications to achieve fuel economy. Methods: In the present work chill cast aluminum alloy matrix hybrid composites having 3 to $12 \mathrm{wt} \%$ of garnet in steps of $3 \mathrm{wt} \%$ and constant $3 \mathrm{wt} \%$ of Carbon, subject to different chilling materials have been developed to study the effect of chilling on microstructure, mechanical properties and dry sliding wear behavior of the composite samples. Metallic and nonmetallic chills were used to study the mechanical and tribological behavior of the samples and compared the same with non-chill cast specimens. The specimens taken from chill end of the casting were tested for their, hardness, tensile strength, fracture and wear behavior. Findings: Out of the results, copper chill is found to be good in improving mechanical properties because of its high Volumetric Heat Capacity (VHC). SEM was used to examine microstructural characterization and worn surfaces of the composite samples. Further, directional cooling with copper chill improves the wear resistance and mechanical behavior of the composites. Application/Improvements: Copper chill cast aluminum alloy hybrid composite reinforced with $9 \mathrm{wt} \%$ garnet and $3 \mathrm{wt} \%$ carbon exhibits better mechanical and tribological behavior and can be used in manufacturing piston in automobile applications.
\end{abstract}

Keywords: Aluminum Hybrid, Copper Chill, Garnet, Stir Cast, Wear

\section{Introduction}

Aluminum matrix hybrid composites with dispersion of two or more ceramic reinforcements have been widely used in various applications of automotive and aerospacesectors ${ }^{1}$. Owing to its light weight, good corrosion resistance and excellent thermal properties these composites are gaining wide popularity as high performance material. Aluminum based hybrid composites shows improved primary and secondary properties over conventional base alloy ${ }^{2,3}$. Ceramic materials generally used to reinforce $\mathrm{Al}$ alloys are $\mathrm{SiC}, \mathrm{TiC}, \mathrm{TiB}_{2}, \mathrm{ZrB}_{2}, \mathrm{AlN}, \mathrm{Si}_{3} \mathrm{~N}_{4}$, $\mathrm{Al}_{2} \mathrm{O}_{3}$ and $\mathrm{SiO}_{2}$. These ceramic materials are with high strength and high hardness. However, it displays brittle behavior and has low resistance to fracture which can be improved by modifying the reinforcement grain size, shape and by incorporating additional phases ${ }^{4}$.
It has been widely reported that Aluminum based alloys can be readily developed with two or more reinforcement and recently there has been a growing interest in the use of hybrid composites. Particulate reinforced hybrid composites exhibit excellent isotropic properties ${ }^{5}$. Stirring action in the casting process will evenly distribute garnet particles on the composite matrix.

Various parameters such as pouring temperature, rotation speed which affect fabrication sound casting have been investigated extensively to optimize the parameters. However further increase in the speed will cause gas bubbles in the composite melt to produce porosity. $\mathrm{In}^{6}$ studied the parameters which affect the solidification of Aluminium alloy. Experiments were carried out on a mold having high cooling rates to show range of solidification temperatures which are influenced by variation of cooling rates. 
Hybrid composites are an alternative approach to tailoring the overall behavior of materials by incorporating insoluble two or more dispersoids to the base matrix ${ }^{7-9}$. Many researchers have exploited the various types of artificial reinforcements in aluminum alloy matrices such as $\mathrm{SiC}$, $\mathrm{SiO}_{2}, \mathrm{Al}_{2} \mathrm{O}_{3}, \mathrm{BN}, \mathrm{B}_{4} \mathrm{C}, \mathrm{WC}, \mathrm{TiC}$, etc to achieve demands of various applications ${ }^{10,11}$. The investigation carried out by ${ }^{12}$ begins with fabrication of $\mathrm{Al} 6063 / \mathrm{Al}_{2} \mathrm{O}_{3} / \mathrm{Gr}$ hybrid composites using liquid metallurgy technique, followed by the wear study using conventional tribometer apparatus for different parameters like sliding speed, applied loads and a discussion of effect of reinforcements. The wear resistance is proportional to dispersoid content. At higher loads, the wear mechanism changes to delamination.

The carbon being soft, grease and ability to withstand very high temperature makes the alloy very high wear resistant and self-lubricating material by forming a tribolayer between the contact surfaces ${ }^{13}$. Microstructural studies have revealed uniform distribution of carbon in the matrix with improves wear behavior. But with increasing carbon content, leads to weakening of matrix and increases wear rate. Hence $3 \mathrm{wt} \%$ of carbon is considered as secondary reinforcement in the current work ${ }^{14,15}$. In studied the influence of graphite on hardness wear property of Al6061 hybrid composite with $\mathrm{Al}_{2} \mathrm{O}_{3}$ and $\mathrm{SiC}$ particulate. It was discovered that addition of Graphite particles decreases the microhardness but immensely improves wear resistance of the samples ${ }^{16}$. In recent years many researchers have worked on the combination of graphite with $\mathrm{SiC}$ and $\mathrm{Al}_{2} \mathrm{O}_{3}$ and found the similar results. $\mathrm{In}^{17}$ investigated effect of chills on wear behavior. In reinforced $1 \mathrm{wt} \% \mathrm{Gr}$ and 10 wt\% $\mathrm{SiC}$ with A356 to investigate the tribological properties. The MML formed by the graphite reduces the wear drastically ${ }^{18}$. Rapid and directional solidification is one of largely accepted method to obtain finer microstructure and improved properties which can be achieved by the application of chills. Although the sand cast composite results in some defects like porosity, the application of chills will improve the directional solidification to achieve finer microstructure with improved mechanical properties.

\section{Experimental Material and Method}

\subsection{Experimental Material}

Commercially available and generally known piston alloy (LM 13), multicomponent Al-Si-Ni-Cu-Mg alloy with lower concentrations of Fe and Mn was used in the present investigation. LM 13 Aluminum alloy matrix exhibits excellent casting properties with reasonable strength. Aluminum has low melting point and high ability to hold the reinforcement. It is suitable for automotive application with its excellent thermo-physical properties. In the present study low cost and naturally available hard ceramic garnets are reinforced in the proportion of $3 \mathrm{wt} \%$ to $12 \mathrm{wt} \%$ in steps of $3 \mathrm{wt} \%$. Based on the literature it was found that various researchers have concluded $3 \mathrm{wt} \%$ range of carbon gives the optimum properties. Hence in the present study constant $3 \mathrm{wt} \%$ carbon is incorporated while developing the hybrid composites. Metallic and non-metallic chills of dimension $25 \mathrm{~mm}$ x $35 \mathrm{~mm}$ x $170 \mathrm{~mm}$ were used to investigate the effect of directional solidification on mechanical properties of the composite. The effect is compared with composites developed without using chills.

\subsection{Experimental method}

\subsubsection{Fabrication of the Composite}

Cost reduction is the key factor for wider application of HMMCs in modern industry which can be achieved by cheaper reinforcements, simpler fabrication methods, and higher production volume. One of the low cost fabrication process stir casting method is used to develop the composites with better bonding of metal matrix with reinforcement particles. Stir casting method is well known for uniform distribution of the reinforcements because of stirring action and flexible for different low melting temperature materials. In the present study Aluminum alloy is melted in a resistance furnace at around $750^{\circ} \mathrm{C}$. Garnet and carbon particulates were preheated to add in the molten matrix reinforced and poured in the sand mold with

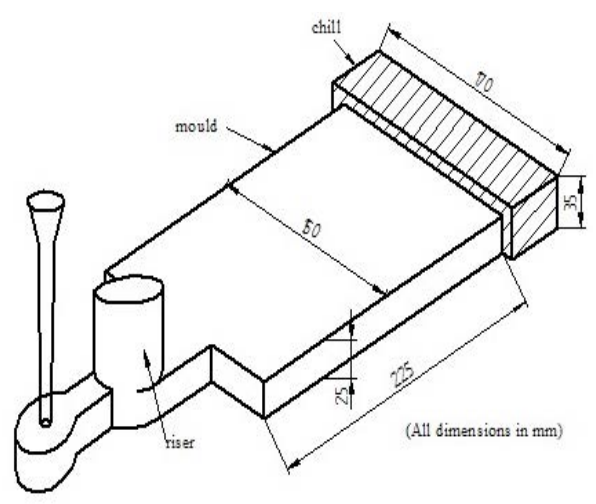

Figure 1. Sand mold with chill. 
different chills such as copper, steel, iron and silicon carbide. One mold without the chill also prepared to compare the results. Figure 1 shows position of the chill in the mold. Specimen is prepared from chill end of the composite to investigate distribution of garnet and carbon in the samples of the composite using Scanning Electron Microscope (SEM).

\subsubsection{Mechanical Properties}

Hardness tests were performed on the composites using Vickers hardness tester with a square-base diamond pyramid as the indenter. This method has received fairly wide acceptance for research work because of its accuracy and flexibility for various materials ranging from DPH of 5 to extremely hard materials with a DPH of 1,500. Ultimate tensile strength of the samples was tested using an electronic tensile testing machine based on ASTM standard. For a particular cast Al-HMMC, three specimens were tested and the mean value along with along with standard deviation of the mechanical properties was reported. The fractured surfaces of the tensile tested specimens were examined in scanning electron microscope. Chill end materials were machined on lathe to get the required dimensions.

\subsubsection{Wear Test}

Specimens of $8 \mathrm{~mm}$ diameter and $30 \mathrm{~mm}$ length were cut from the chill end of the composite. Dry sliding wear behavior of the samples was studied using a pin-on-disc wear testing machine (Figure 2) as per ASTM G-99-95. All the tests were performed on hybrid composite pins at

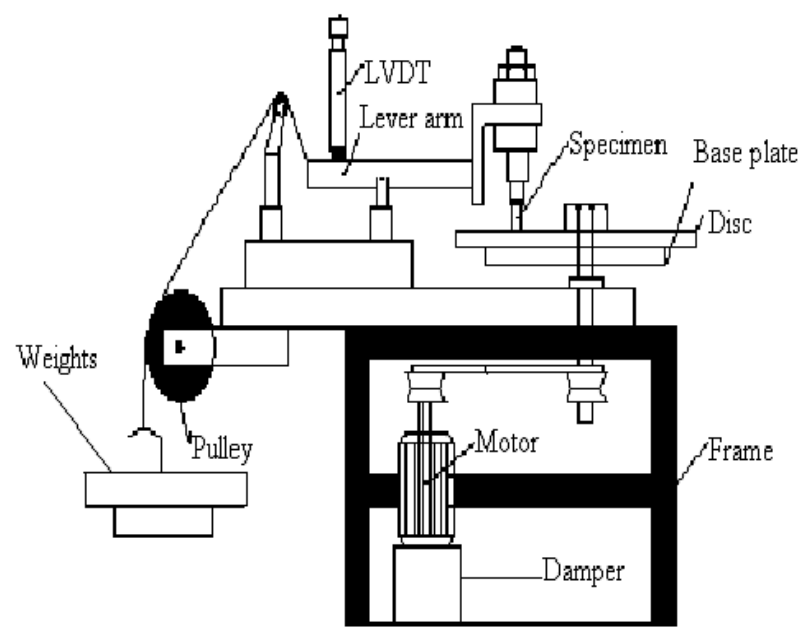

Figure 2. Pin-on-disc test setup. different loads 10 to $50 \mathrm{~N}$ in steps of $10 \mathrm{~N}$ for a sliding distance of $1500 \mathrm{~m}$. For each test, the pin was cleaned with acetone and weighed accurately using a digital electronic balance of accuracy $0.1 \mathrm{mg}$. Each test was repeated for 3 times and the average results were taken.

\section{Results and Discussion}

\subsection{Microstructure and Mechanical Behavior}

Figure 3 shows the optical micrograph of microstructure of the samples. It shows the uniform distribution of the reinforcements and good bonding between reinforcement and matrix. Although in situ process is known for better bonding between matrix and reinforcements it is not developed for mass production. However stir casting method is simple and convenient which is used by many researchers for successful fabrication of the composite. Figure 4 shows the graph of hardness behavior of the chill cast composites for various weight percentage of garnet. It is observed that hardness of the samples increases as the weight percentage of the reinforcement's increases up to $9 \mathrm{wt} \%$ garnet. Afterwards it slightly decreases for higher $w t \%$ of the garnet. The possible reason for higher hardness could be the fact that the hard garnet act as barriers to the movement of the dislocations within the matrix. Various other researchers have also reported that the addition of hard ceramic particulates to metal alloys could lead to improved strength and hardness.

Figure 5 shows the graph of ultimate tensile strength of the samples with respect to various wt $\%$ of the reinforcements for different chill materials. It is noted that ultimate tensile strength of the hybrid composite increases with the addition of garnet and reaches maximum for 9 wt.\% garnet with copper chill material composite. It can be found that the tensile strength of the hybrid samples is higher than the matrix alloy LM 13 and single reinforced composite. Addition of graphite has profound effect on the improvement in the tensile strength of composite. The increase in tensile strength can be attributed by the presence and relatively good dispersion of reinforcement mixture. Similar results were found by ${ }^{19} \mathrm{Al} / \mathrm{Al}_{2} \mathrm{O}_{3} / \mathrm{Gr}$ hybrid composites developed by stir casting process.

\subsection{Fracture Surface Analysis}

The SEM micrograph of the fractured surface of chill cast composite is shown in Figure 6. Figure 6(a) shows the fracture of $9 \mathrm{wt} \%$ garnet with ductile fracture with large 

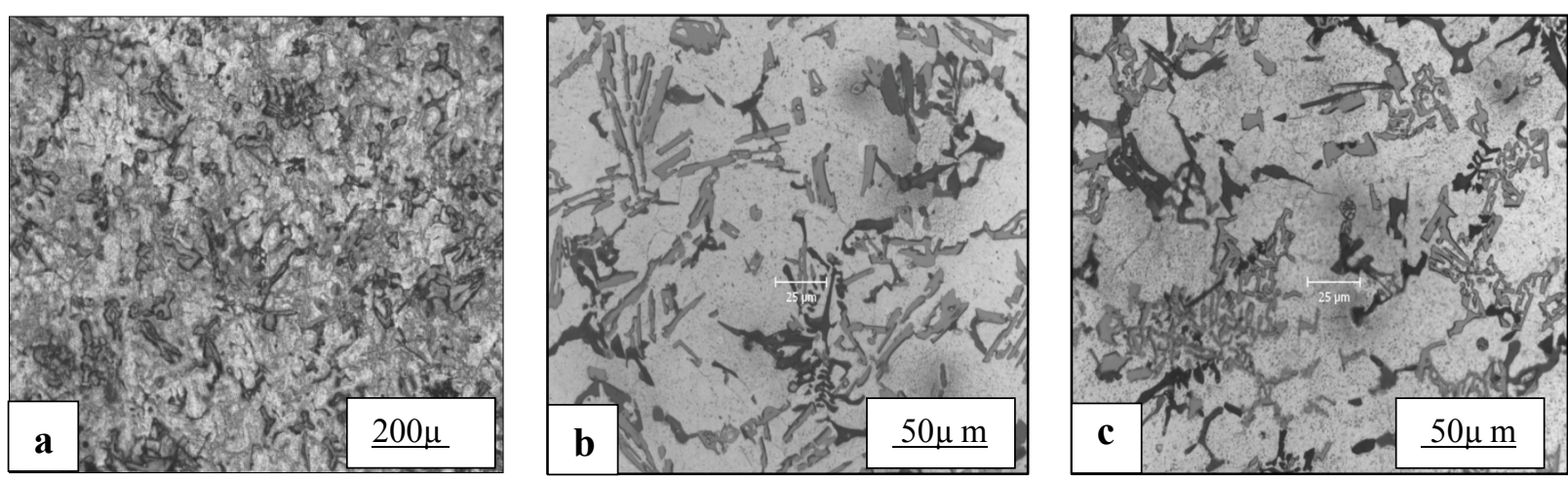

Figure 3. Microstructure of chill cast HMMC.

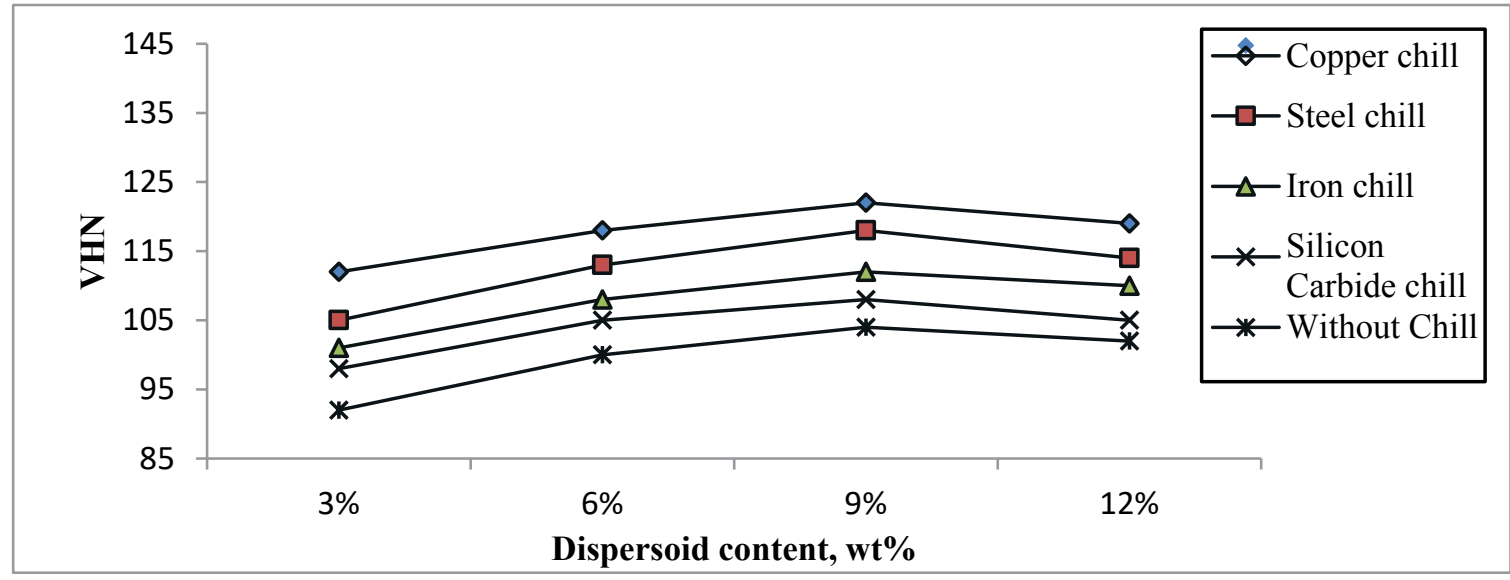

Figure 4. Hardness vs. dispersoid content of hybrid MMCs.

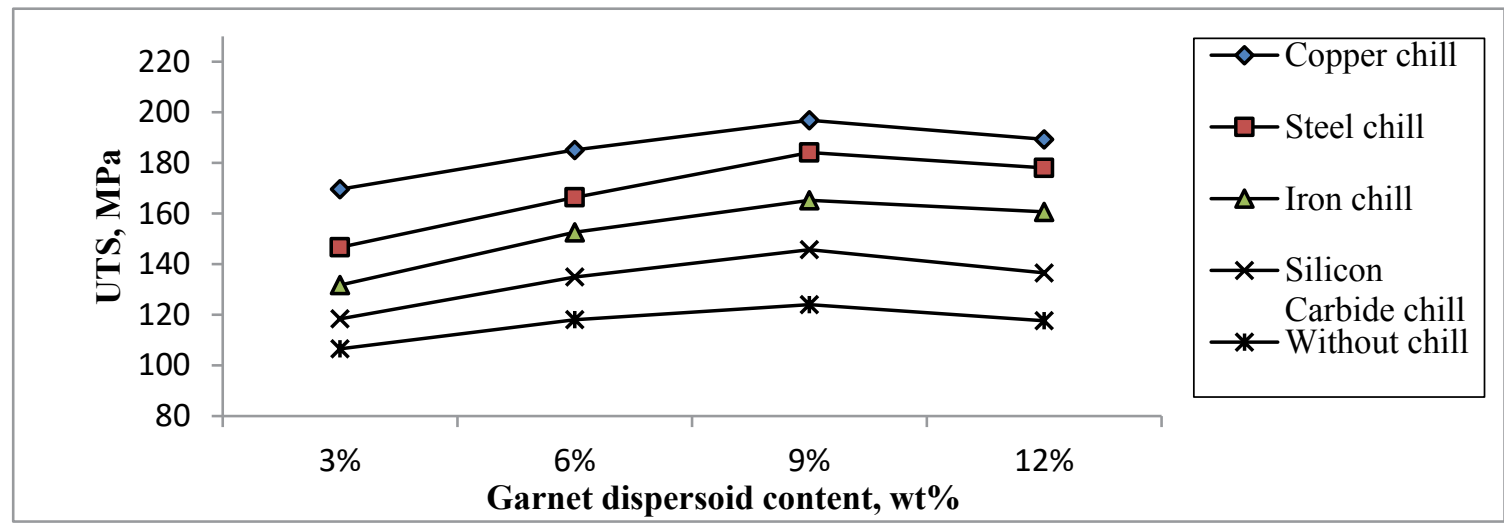

Figure 5. Strength vs. dispersoid content of hybrid MMCs.

cleavage. Figure 6(b) shows the fracture of $12 \mathrm{wt} \%$ garnet composite with brittle fracture with number of dimples on the surface. Ductile fracture of a metal occurs after extensive plastic deformation and is characterized by slow crack propagation. If an applied stress to the specimen exceeds its ultimate tensile strength and is sustained long enough, the specimen will fracture. Brittle fracture could be due to over loading, improper design, selection of materials or improper fabrication. It occurs with very little plastic deformation. The fracture toughness of the hybrid composites reinforced with garnet and carbon increased with increase in garnet contents. 


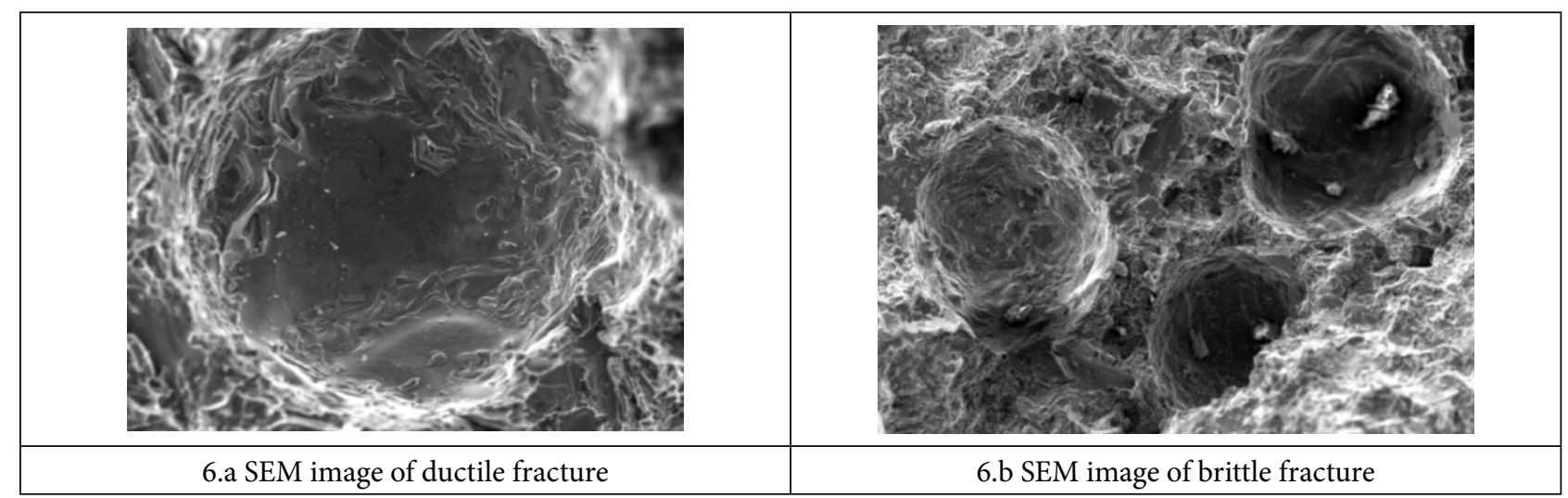

Figure 6. (a). SEM image of ductile fracture. (b) SEM image of brittle fracture.
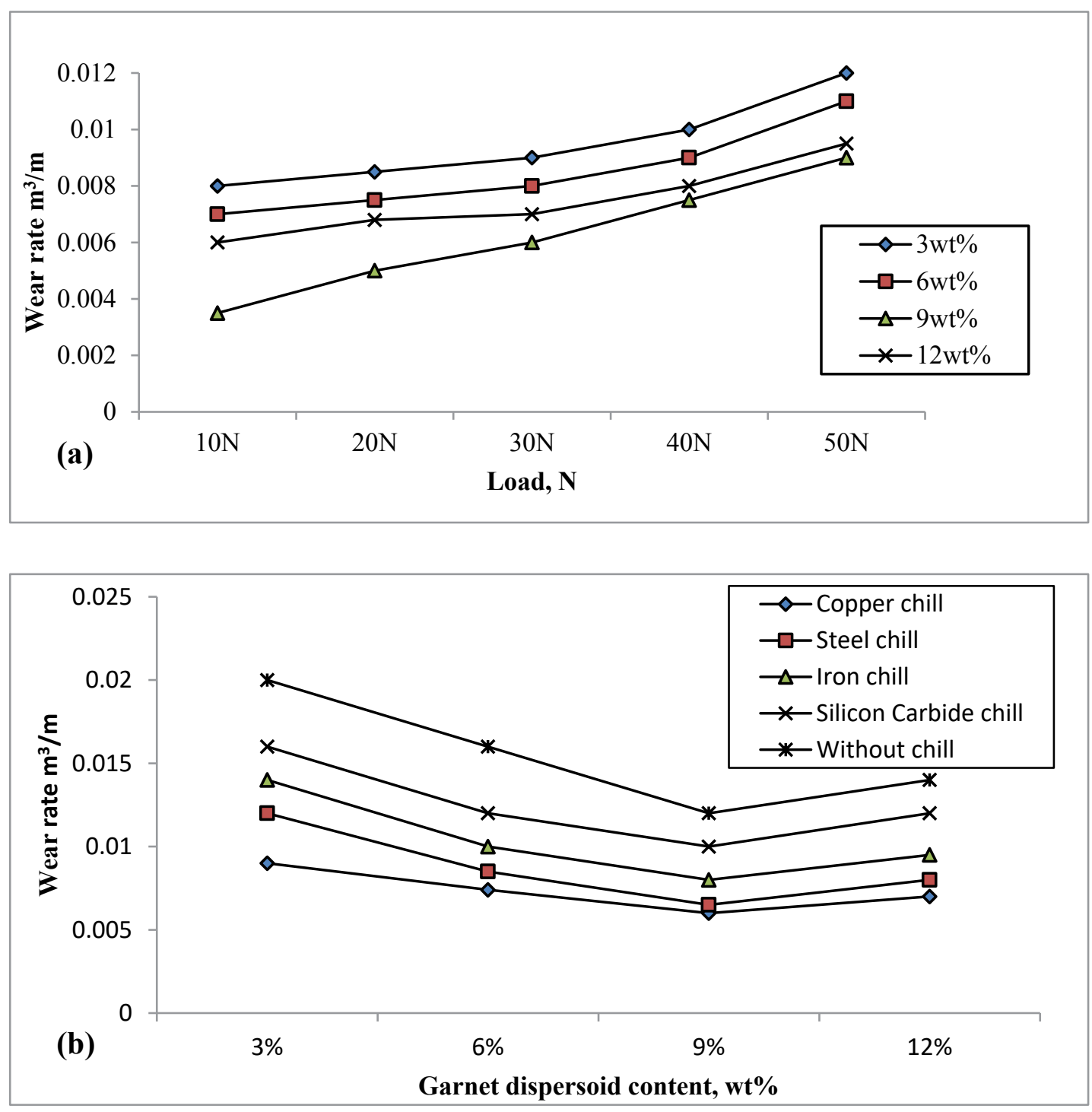

Figure 7. (a) Wear rate of copper chilled composite vs. load for different wt $\%$ of garnet (b) Wear rate of different chilled hybrid MMCs vs. wt\% of garnet. 


\subsection{Wear Behavior}

The influence of the weight fraction of garnet as well as variation of load on the weight loss of hybrid composites is shown in Figure 7. Figure 7(a) shows the variation of the weight loss for the samples consisting $9 \mathrm{wt} \%$ garnet with copper chill. It can be seen that, as the load increases from $10 \mathrm{~N}$ to $50 \mathrm{~N}$ weight loss increases for all wt\% of garnet. However, up to $30 \mathrm{~N}$, weight loss gradient was less compared to the higher load of $40 \mathrm{~N}$ and $50 \mathrm{~N}$. Is is also found that weight loss was decreased with increasing weight percentage of the reinforcement's up to $9 \mathrm{wt} \%$ of garnet (Figure 7(b)). This is due to the fact that garnet particles prevent the movement of dislocation and act as the obstacles wear. The garnet particles in the matrix alloy strengthen the softer matrix limiting the deformation of the sliding surface. This result is a good agreement with the result of ${ }^{20}$.

Figure 8 (a-d) shows the worn surface of the $9 \mathrm{wt} \%$ garnet with chill cast at various loads. Figure 8(a) wear behavior at low load of $10 \mathrm{~N}$ with fine scratches 8 (b) shows the finer grooves and scratches for $30 \mathrm{~N}$. These grooves will be deeper in 8(c) for $40 \mathrm{~N}$ and Figure 8(d) shows the sharp groove for higher load of $50 \mathrm{~N}$. As the load increases the friction between contacting surfaces will be higher and hard ceramic particles forms the grooves and scratches on the surface. The pulling out of the hard garnet particles for higher loads results in delamination wear in the composite. Figure 9 shows the EDX image of worn surface of aluminum hybrid composite with $9 \mathrm{wt} \%$ garnet and $3 \mathrm{wt} \%$ carbon. It shows the various composition of the sample and the presence of $O$ in the image proves the formation of tribolayer between the contacting surfaces.

\section{Conclusions}

ASTM LM 13 Aluminum alloy was successfully synthesized with garnet and carbon using stir casting method. Optical micrograph and SEM confirms the uniform dispersion of the reinforcements with good bonding with the matrix.

EDX test justify the right proportion of the composition in the specimens. Samples cast using copper chill block
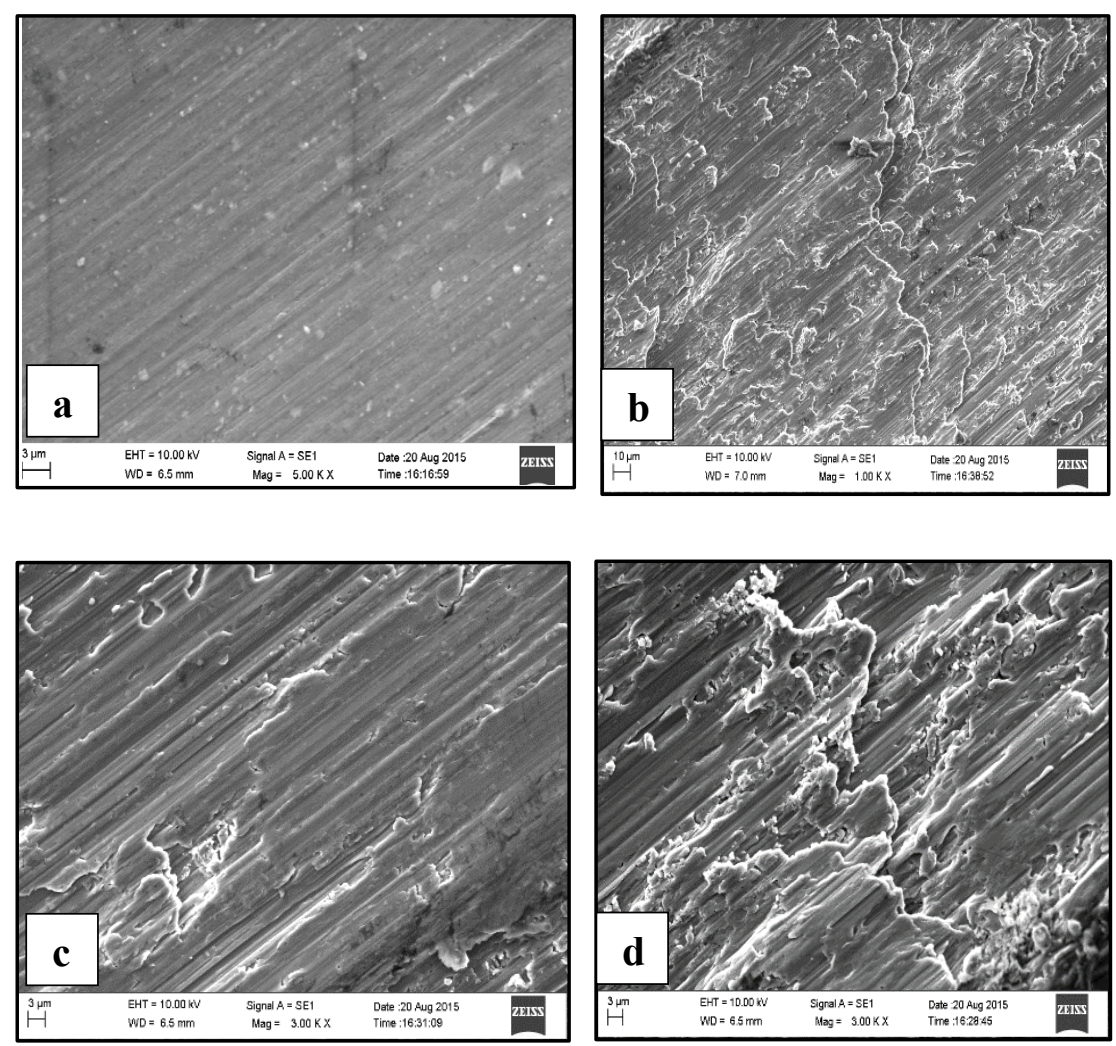

Figure 8. (a) SEM image of Granet-9 wt $\% / C-3$ wt $\%$ copper chilled HMMC tested at $10 \mathrm{~N}$, (b) SEM image of Granet-9 wt $\% / C-3$ wt $\%$ copper chilled HMMC tested at 20 N, (c) Granet-9 wt\%/C-3 wt\% copper chilled HMMC tested at 30 N, (d) tested at $50 \mathrm{~N}$. 


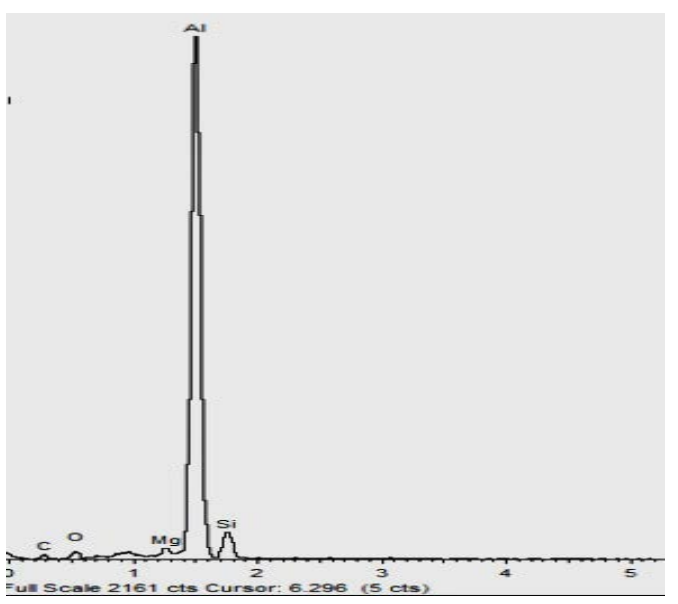

Figure 9. EDX Spectrum of worn surface of Al/Garnet-9 wt $\% / C-3$ wt\% copper chilled HMMC.

shows the significant improvement in mechanical properties. The test result showed that these MMCs were greatly influenced by the Garnet particles addition and chilling effect. Fracture behavior changes from ductile to brittle as the weight percentage of reinforcement increases in the matrix. The composite exhibits superior wear resistance up to $9 \mathrm{wt} \%$ garnet $+3 \mathrm{wt} \%$ carbon with copper chilling. At 12 wt $\%$ of garnet it exhibits delamination wear. Presence of a uniform graphite layer on top of the worn surface helped to decrease the wear loss. Hence the composites could be substitute for automobile applications.

\section{References}

1. Sharma P. A study on microstructure of Aluminium matrix composites. IntegrativeMedicineResearch.2015;3(3):240-4. https://doi.org/10.1016/j.jascer.2015.04.001

2. Devaraju A. Influence of reinforcements $\left(\mathrm{SiC}\right.$ and $\mathrm{Al}_{2} \mathrm{O}_{3}$ ) on wear and mechanical properties of Aluminum alloy 6061-T6 based surface hybrid composites. Materials and Design. 2013; 51:331-41. https://doi.org/10.1016/j.matdes.2013.04.029

3. Sarada BN. Hardness and wear characteristics of hybrid Aluminium metal matrix composites produced by stir casting technique. Materials Today: Proceedings. 2015; 2(4-5):2878-85. https://doi.org/10.1016/j.matpr.2015.07.305

4. Aruri D. Wear and mechanical properties of 6061-T6 Aluminum alloy surface hybrid composites [(SiC-Gr) and $\left.\left(\mathrm{SiC}-\mathrm{Al}_{2} \mathrm{O}_{3}\right)\right]$. Integrative Medicine Research. 2013; 2(4):362-9. https://doi.org/10.1016/j.jmrt.2013.10.004

5. Sharifi EM. Wear behavior of Aluminum matrix hybrid nanocomposites fabricated by powder metallurgy.
Wear. 2011; 271(7-8):1072-9. https://doi.org/10.1016/j. wear.2011.05.015

6. Hemanth J. Effect of high rate heat transfer during solidification using water-cooled chills on mechanical behavior. Materials and Design. 2003; 24:37-45. https://doi. org/10.1016/S0261-3069(02)00086-9

7. Radhika N. Effect of reinforcement on wear behavior of Aluminium hybrid composites. Tribology-MSI. 2003; 7(1):36-41. https://doi.org/10.1179/1751584X 13Y.0000000025

8. Mohan Kumar S. Evaluation of fracture toughness and mechanical properties of Aluminum alloy 7075, T6 with nickel coating. Procedia Engineering. 2014; 97:178-85. https://doi.org/10.1016/j.proeng.2014.12.240

9. Bakshi SR. Surface and coatings technology microstructure and wear properties of Al-Si composite coatings prepared by cold spraying. Surface and Coatings Technology. 2009; 204(4):503-10. https://doi.org/10.1016/j.surfcoat.2009.08.018

10. Basavarajappa S. Dry sliding wear behavior of $\mathrm{Al} / \mathrm{SiC} /$ Gr hybrid composites. Journal of Materials Engineering and Performance. 2006; 15:668-74. https://doi. org/10.1361/105994906X150803

11. Anju S. Effect of particle size on wear behavior of Al-garnet composites. Particulate Science and Technology. 2015; 33:234-39. https://doi.org/10.1080/02726351.2014.954686

12. Saravanakumar A. Synthesis and mechanical behavior of $\mathrm{Al} 6063 / \mathrm{Al}_{2} \mathrm{O}_{3} / \mathrm{Gr}$ hybrid composites. Procedia Engineering. 2014; 97:951-60. https://doi.org/10.1016/j. proeng.2014.12.371

13. Babi M. Wear properties of A356/10SiC/1Gr hybrid composites in lubricated sliding conditions. Tribology in Industry. 2013; 35(2):148-54.

14. Kumar NM. An investigation of mechanical properties and corrosion resistance of $\mathrm{Al} 2618$ alloy reinforced with $\mathrm{Si}_{3} \mathrm{~N}_{4}$, AlN and $\mathrm{ZrB}_{2}$ composites. Journal of Alloys and Compounds. 2015; 652:244-9. https://doi.org/10.1016/j. jallcom.2015.08.205

15. Umanath K. Analysis of dry sliding wear behavior of Al6061/SiC/ $/ \mathrm{Al}_{2} \mathrm{O}_{3}$ hybrid metal matrix composites. Composites Part B: Engineering. 2013; 53:159-68. https:// doi.org/10.1016/j.compositesb.2013.04.051

16. Uthayakumar M. Wear performance of Al-SiC-B4C hybrid composites under dry sliding conditions. Materials and Design. 2013; 47:456-64. https://doi.org/10.1016/j.matdes.2012.11.059

17. Assessment of dispersoid content and chill effect for improved mechanical properties of chilled $\mathrm{Al}$ alloy composite. 2008. https://www.researchgate.net/ publication/267590694_Assessment_of_Dispersiod_ 
Content_and_Chill_Effect_for_Improved_Mechanical_ Properties_of_Chilled_Aluminium_Alloy_Quartz_ Particulate_Composite

18. Babic M. Wear behavior of aluminum matrix hybrid nanocomposites fabricated by powder metallurgy. Wear. 2011; 271(7-8):1072-9. https://doi.org/10.1016/j. wear.2011.05.015
19. Gaitonde VN. Some studies on wear properties of $\mathrm{Al} / \mathrm{Al}_{2} \mathrm{O}_{3} /$ Gr hybrid composites. Journal of Minerals and Materials Characterization and Engineering. 2012; 11:695-703. https://doi.org/10.4236/jmmce.2012.117055

20. Padmavathi KR. Tribological behavior of Aluminium hybrid metal matrix composite. Procedia Engineering. 2014; 97:660-7. https://doi.org/10.1016/j.proeng.2014.12.295 